\title{
EL MAPA DE LA POLÍTICA DE COLONIZACIÓN EN ANDALUCÍA
}

\author{
Josefina Cruz Villalón *
}

\section{RESUMEN}

La política de colonización ha tenido una gran trascendencia en Andalucía, ya que es la responsable directa de la transformación de más de 250.000 hectáreas en regadío, así como de la construcción de unos 130 poblados en la región.

En esta comunicación se analizan los resultados de esta vasta operación de intervención sobre el territorio y se hace una reflexión sobre su eficacia en términos económicos, sociales y medioambientales, el contexto de la actual política agraria comunitaria.

\section{RÉSUMÉ}

La politique de colonisation a eu une grande transcendance en Andalousie, puisqu'elle est la responsable directe de la transformation en irrigation de plus de 250.000 hectares, ainsi que de la construction de quelques 130 villages dans la région.

Dans cette communication, on analyse les résultats de cette très étendue opération d'intervention sur le territoire et on fait una réflexion sur leur efficacité au point de vue de l'economie, la société et l'environnement, dans le contexte de l'actuelle Politique Agraire Commun.

\section{Introducción}

En Andalucía la política de colonización a lo largo de toda la presente centuria se identifica, esencialmente, con la política de transformación de tierras en regadío. Complementaria, o subsidiariamente, esta política ha supuesto asimismo el reparto de parte de las tierras transformadas en pequeños lotes, así como la construcción de poblados de nueva

\footnotetext{
* Universidad de Sevilla.
} 
planta para dar alojamiento a los beneficiarios del reparto, los colonos, y, en cierta medida, para modificar el mapa del poblamiento rural en Andalucía, caracterizado tradicionalmente por su elevado grado de concentración en grandes núcleos rurales.

Pero decimos complementaria o subsidiariamente porque, si bien éstos fueron unos objetivos reiteradamente declarados y en concreto el reparto de tierras a colonos ha constituido buena parte de la base ideológica para la justificación de la intervención pública, por sus resultados, la política de colonización ha de ser interpretada hoy como una intervención pública para la transformación de tierras en regadío, como una política de modernización de la agricultura tradicional andaluza, como una política, en suma, más económica que social.

Pero hoy la política de regadío está siendo fuertemente cuestionada. Con independencia de la fuerte presión coyuntural que en este cuestionamiento pueda tener la prolongada sequía que afecta a la Península Ibérica, sobre todo al sureste peninsular, la puesta en cuestión de la expansión del regadío se sustenta, por una parte, en la escasez del recurso agua, en la competencia en su uso por parte de distintas actividades económicas, o entre las actividades económicas y la conservación medioambiental o las necesidades humanas, y en la constatación de que entre el $75 \%$ y el $80 \%$ del agua que consumimos se dedica a regadío.

Por otra parte, se cuestiona el fin último del regadío. Durante decenios la expansión del regadío ha sido identificada, al menos en el sur de la Península Ibérica, con una política de modernización de la agricultura, como una política de incremento de la producción y de la productividad; es más: el desarrollo agrario ha sido considerado como base del desarrollo económico. Y ello en un contexto en el que, como recoge la Memoria del Anteproyecto del Plan Hidrológico Nacional, «la obtención de nuevos recursos era relativamente fácil, los límites para su utilización no se vislumbraban y la preocupación por los problemas ambientales y la calidad del agua apenas existían». Pero en el contexto de la actual política agraria de la Unión Europea, caracterizado por excedentes agrarios en la mayor parte de las producciones agrícolas y ganaderas y por los elevados costes presupuestarios derivados del sostenimiento de su sector agrario, la tendencia generalizada, o genéricamente defendida (aunque habría que matizar esta idea), es la de la reducción de las producciones agrarias. Y en este marco resulta, en principio, difícilmente defendible una política de crecimiento del regadío, incluso la del mantenimiento de la actual superficie regada.

Parece, pues, que nos encontramos en el momento oportuno para reflexionar sobre el resultado de la política de colonización, o política de regadío, en Andalucía, con la intención de contribuir a orientar futuras políticas agrarias, o futuras políticas sobre el agua.

Centraremos esta reflexión en varios aspectos. En términos territoriales, analizaremos los resultados de esta política en el volumen de tierra transformadas y su ubicación, así como en la localización y evolución de los poblados de colonización construidos; ambos elementos nos proporcionarán el mapa de colonización en Andalucía. En términos estrictamente socio-económicos analizaremos la eficacia del regadío valorando simultáneamente el valor de la producción, el empleo generado y el consumo de agua de las grandes zonas regables andaluzas.

\section{La superficie transformada en regadío}

En Andalucía, la superficie transformada en riego como resultado de la intervención de las administraciones públicas supera las 250.000 hectáreas (253.863 has.). Este volumen supone en torno al $40 \%$ del total de la superficie actualmente considerada de regadío en la región. De ambos valores, volumen y porcentaje, puede fácilmente deducirse la importan- 


\begin{tabular}{|c|c|c|}
\hline & $\begin{array}{c}\text { Sup. en riego } \\
\text { (HAS) }\end{array}$ & $\begin{array}{c}\text { en transformac. } \\
\text { (HAS) }\end{array}$ \\
\hline \multicolumn{3}{|l|}{ CUENCA DEL GUADALOUIVIR } \\
\hline ALMONTE-MARIMAS & 6.009 & \\
\hline VEGA DE CORIA & 1.317 & \\
\hline BAJO GUADALQUIVIR & 46.454 & \\
\hline TRAMO FINAL DEL GUADALQUIVIR & 3.350 & \\
\hline ARROYO SALADO MORON & 1.476 & \\
\hline VIAR & 11.330 & \\
\hline VALLE INFERIOR & 18.494 & \\
\hline GENIL (M.D.) & 2.118 & \\
\hline BEMBEZAR & 15.372 & \\
\hline GENIL-CABRA, & 20.749 & 24.083 \\
\hline PALMA DEL RÍO & & 3.070 \\
\hline LOS HUMOSOS & & 2.514 \\
\hline RÍO CORBONES & & 3.424 \\
\hline GUADALMELLATO & 7.720 & \\
\hline FUENTE PALMERA & 5.260 & \\
\hline MARUANAS-CHARCO RIAÑEZ & 1.981 & \\
\hline SIERRA BOYERA & 1.153 & \\
\hline SALADO DE ARJONA & 4.500 & \\
\hline RUMBLAR & 5.642 & \\
\hline MENGIBAR & 4.316 & \\
\hline VEGAS (ALTAS, MEDIAS Y BAJAS) & 11.158 & \\
\hline GUARRIZAS & & 12.000 \\
\hline VILCHES & & 2.500 \\
\hline JANDULILLA & 2.000 & \\
\hline DONADIO C-400 & & 2.505 \\
\hline GUADALEN & 780 & \\
\hline GUALDAMENA & 2.711 & \\
\hline GUADALENTÍN & 5.801 & \\
\hline ALGAIDA & 1.000 & \\
\hline CACIN & 5.614 & \\
\hline \multicolumn{3}{|l|}{ CUENCA DEL GUADALETE-BARBATE } \\
\hline COSTA N.O. & 5.858 & 3.238 \\
\hline GUALDALCACÍN & 11.301 & \\
\hline BORNOS & 2.089 & \\
\hline GUADALETE & 1.519 & \\
\hline BARBATE & 4.500 & \\
\hline VILLAMARTÍN & 3.054 & \\
\hline \multicolumn{3}{|l|}{ CUENCA SUR } \\
\hline GUADARRANQUE & 2.530 & 1.470 \\
\hline GUADALHORCE & 12.500 & \\
\hline LLANOS DE ANTEQUERA & 2.646 & \\
\hline GUARO & 4.016 & \\
\hline MOTRIL-SALOBREÑA & 2.986 & \\
\hline CAMPO DE DALÍAS & 11.416 & \\
\hline CAMPO DE NÍJAR & 1.742 & \\
\hline EL SALTADOR & 2.594 & \\
\hline LOS GUIRAOS & 218 & \\
\hline EL HIGUERAL & 600 & \\
\hline CUEVAS DEL ALMANZORA & 2.079 & \\
\hline \multicolumn{3}{|l|}{ CUENCA DEL GUADIANA } \\
\hline CHANZAS & 5.814 & 11.852 \\
\hline VALDEMARÍA & & 1.075 \\
\hline CORUMBEL & & 1.306 \\
\hline
\end{tabular}

Fuente: I.A.R.A., 1994. 


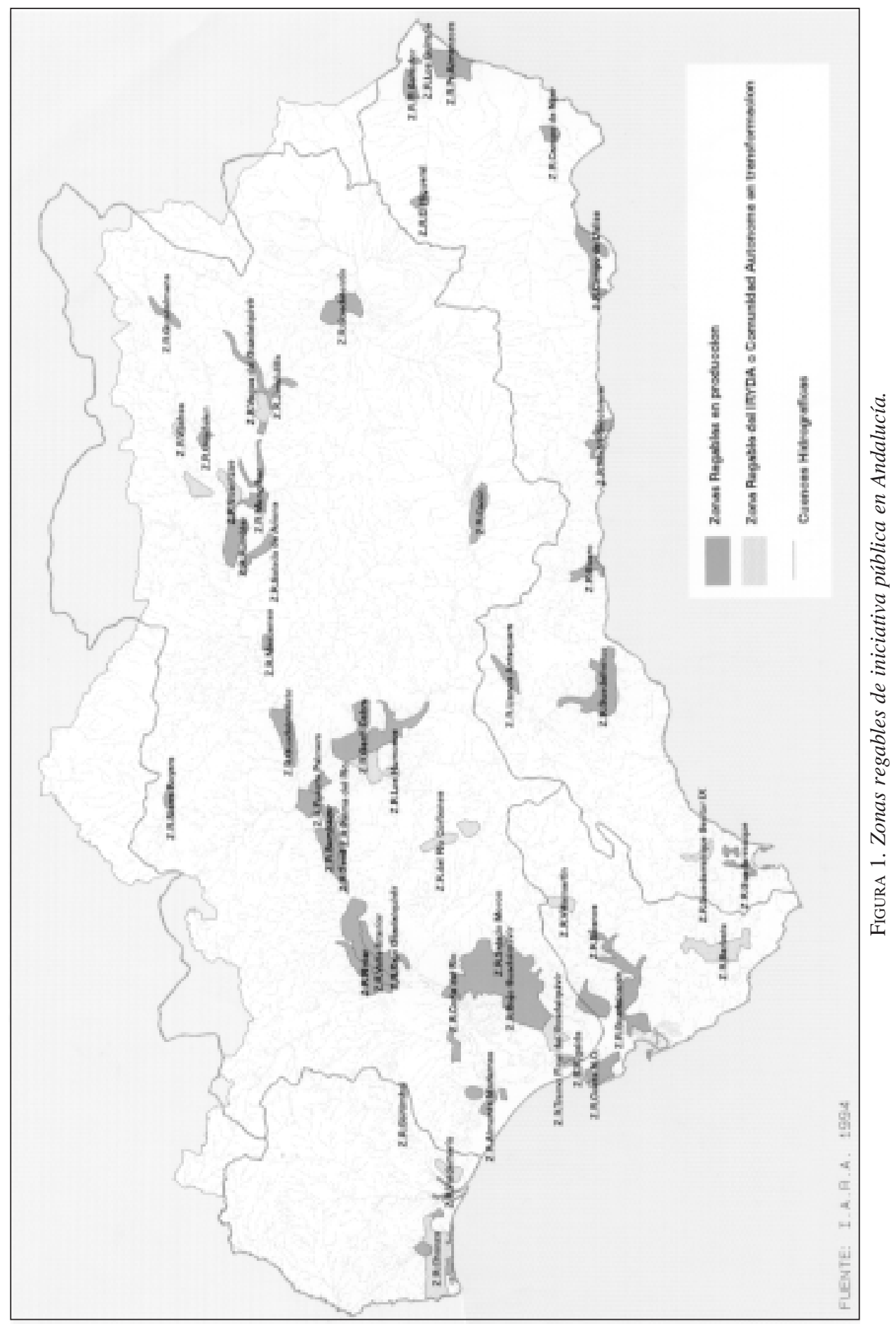


cia decisiva que la intervención pública ha tenido en la transformación de tierras en regadío en la región andaluza.

Como puede apreciarse en la tabla 1 y en la figura 1 , el mayor volumen de tierras transformadas se localizan en la cuenca del Guadalquivir, tanto por la mayor extensión de ésta como por la mejor aptitud de sus tierras para la transformación; pero también por la ausencia histórica del regadío en las campiñas bajoandaluzas. Efectivamente, más del 70\% de las tierras puestas en regadío por intervención pública en Andalucía se localizan en la cuenca del Guadalquivir, un $20 \%$ en la Cuenca Hidrográfica del Sur, un $8 \%$ en la del Guadalete-Barbate y apenas un $2 \%$ en la del Guadiana.

En términos de superficie, la operación de mayor envergadura es la de la Zona Regable del Bajo Guadalquivir con más de 46.000 hectáreas transformadas; esta operación se lleva a cabo lentamente a lo largo de las décadas de los sesenta y setenta, y se realiza sobre terrenos en su mayor parte incultos, pues corresponden bien a las marismas de la margen izquierda del Guadalquivir, bien a terrenos con suelos muy salinos, de borde de las marismas, de escasos aprovechamientos. Hubo asimismo una propuesta de transformar en regadío otras 45.000 hectáreas en la margen derecha de las marismas (Plan AlmonteMarismas) y junto al Parque Nacional de Doñana, que por diversas causas ha visto sensiblemente reducida la superficie pública de riego; pero que de haber prosperado hubiera creado una gran mancha de casi 100.000 hectáreas de regadío público en las proximidades de la desembocadura del Guadalquivir.

Pero, salvo en este caso y en el de los arenales subdesérticos de la provincia de Almería, en la mayor parte de las intervenciones se transforman, en tierras de regadío, terrenos dedicados al cultivo de secano, en muchas casos terrenos de vega. Entre éstas y por su extensión cabe asimismo destacar la unidad formada por la Zona Regable del Valle Inferior y la del Viar, en la provincia de Sevilla y al noreste de la aglomeración urbana de la capital, con casi 30.000 hectáreas en conjunto; o la Zona Regable del Genil-Cabra, a caballo entre las provincias de Sevilla y Córdoba, y ocupando las campiñas del principal afluente del Guadalquivir por su margen izquierda. En la Cuenca Hidrográfica del Sur destaca, por su extensión, la Zona Regable del Guadalhorce, al noroeste de la aglomeración urbana de Málaga, con 12.500 hectáreas; y por su alta productividad los regadíos almeriense del Campo de Dalías y Campo de Níjar, abastecidos por acuíferos.

En términos generales, y con pocas excepciones como la antecedente, el regadío de iniciativa pública en Andalucía ha tendido a ocupar tierras bajas y las vegas de los principales ríos de la región, basándose en un sistema de embalse-canal de derivaciónsuperficie regable (en función de la cota dominada por el canal de derivación). Este mapa del regadío público se une, sin solución de continuidad, con las tierras puestas en regadío por iniciativa privada.

A pesar de la polémica abierta acerca de la oportunidad o conveniencia, o incluso capacidad, de continuar ampliando la superficie de regadío, lo cierto es que en la actualidad en Andalucía se encuentra en transformación en regadío en torno a unas 80.000 hectáreas más. En parte, estas operaciones son ejecutadas por la Administración Central, a través del I.R.Y.D.A., debido a la lentitud con la que se ejecutan estas obras, ya que estas competencias en materia agraria fueron transferidas a la Comunidad Autónoma de Andalucía hace más de una década; y en parte responden a la iniciativa de la Administración Autonómica, que bien por inercia o por propia convicción ha continuado con la política de creación de nuevos regadíos en la región.

Pero la política de regadío está experimentando también una reorientación al dedicarse buena parte de los recursos a la denominada genéricamente «mejora del regadío», y cuyas actuaciones van encaminadas en parte de la sustitución o modernización de los antiguos 
sistemas de canalización, distribución y/o riego; y en parte a la mejora de secanos mediante la disponibilidad de riegos ocasionales, pero sin que ello suponga una intervención ni en la estructura de la explotación, ni nuevas parcelaciones o la introducción de nuevos cultivos.

\section{Los poblados de colonización}

La construcción de nuevos poblados en las zonas en las que se procedía a su transformación en regadío aparecía suficientemente justificada, a pesar del coste que ello suponía en el conjunto de la operación, por distintas razones, unas de carácter productivo, otras territoriales e incluso otras de carácter ideológico.

Básicamente, y debiéndonos para ello situarnos en el contexto económico y territorial de la España de la primera mitad del siglo (especialmente, por lo que al grado de desarrollo de las comunicaciones hace referencia), la justificación de la construcción de poblados de colonización se encuentra, en primer lugar y sobre el supuesto de que esas tierras iban a ser repartidas en pequeños lotes a nuevos agricultores, en la conveniencia de situar la residencia del nuevo colono junto a sus tierras, encontrándose textos del antiguo Instituto Nacional de Colonización en los que la distancia entre la parcela y la residencia se fija, como valor óptimo, en 2,5 kilómetros, lo que significaría una distancia de 5 kilómetros entre poblados.

También, un factor que sin duda contribuyó a la opción por la construcción de nuevos poblados de colonización fue las características del hábitat rural tradicional de Andalucía, fuertemente concentrado (rasgo que es común a otras de las dos comunidades donde mayor incidencia ha tenido la política de colonización: Extremadura y Aragón). Ello, por una parte, desaconsejaba la edificación de viviendas aisladas, dentro de la propia parcela, que chocaba abiertamente con la cultura rural andaluza; y por otra, aconsejaba la creación de nuevos poblados, debido a la distancia entre los núcleos rurales existentes, o por inexistencia de poblamiento en las tierras que se transforman (Bajo Guadalquivir, Campo de Dalías). De todos modos, en algunos casos, y atendiendo al menor volumen de las tierras repartidas, se edificaron algunas viviendas aisladas, que no llegan a formar núcleo de población.

Pero, además, existía la convicción entre los planificadores del Instituto Nacional de Colonización de que con la creación de estos nuevos poblados se llegaría a consolidar un colectivo fuertemente vinculado a la tierra, lo que contribuiría a la perdurabilidad de la operación y a la formación de un grupo social de pequeños agricultores, de escasa presencia en la agricultura española en general, y andaluza en particular.

$\mathrm{Y}$, sin duda, al tratarse de operaciones que suponían una gran transformación territorial, dentro de la concepción faraónica que en ocasiones se tenía de la misma, hubo de constituir un gran reto para muchos de estos planificadores la construcción de una ciudad de nueva planta, lo que les daba la oportunidad de concebir ex novo la organización física y social de todo un nuevo asentamiento de población.

Así, la construcción de nuevos poblados, varios en cada nueva Zona Regable, fue un elemento consustancial a la transformación de tierras en regadío y el reparto de parcelas a pequeños agricultores. Estos poblados de nueva planta fueron concebidos como sociedades autosuficientes (una vez más hay que situarse en el contexto español de los primeros decenios del siglo, para valorar esta opción), para dar cobijo a una población que contaría entre 500 y 1.000 habitantes, de media. Tomando en consideración que unos de los criterios de selección de colonos fue el del número de hijos que tuviera el aspirante, y que eran familias con cinco o seis miembros de media, se trataba de poblados pensados para 80 a 200 familias. 


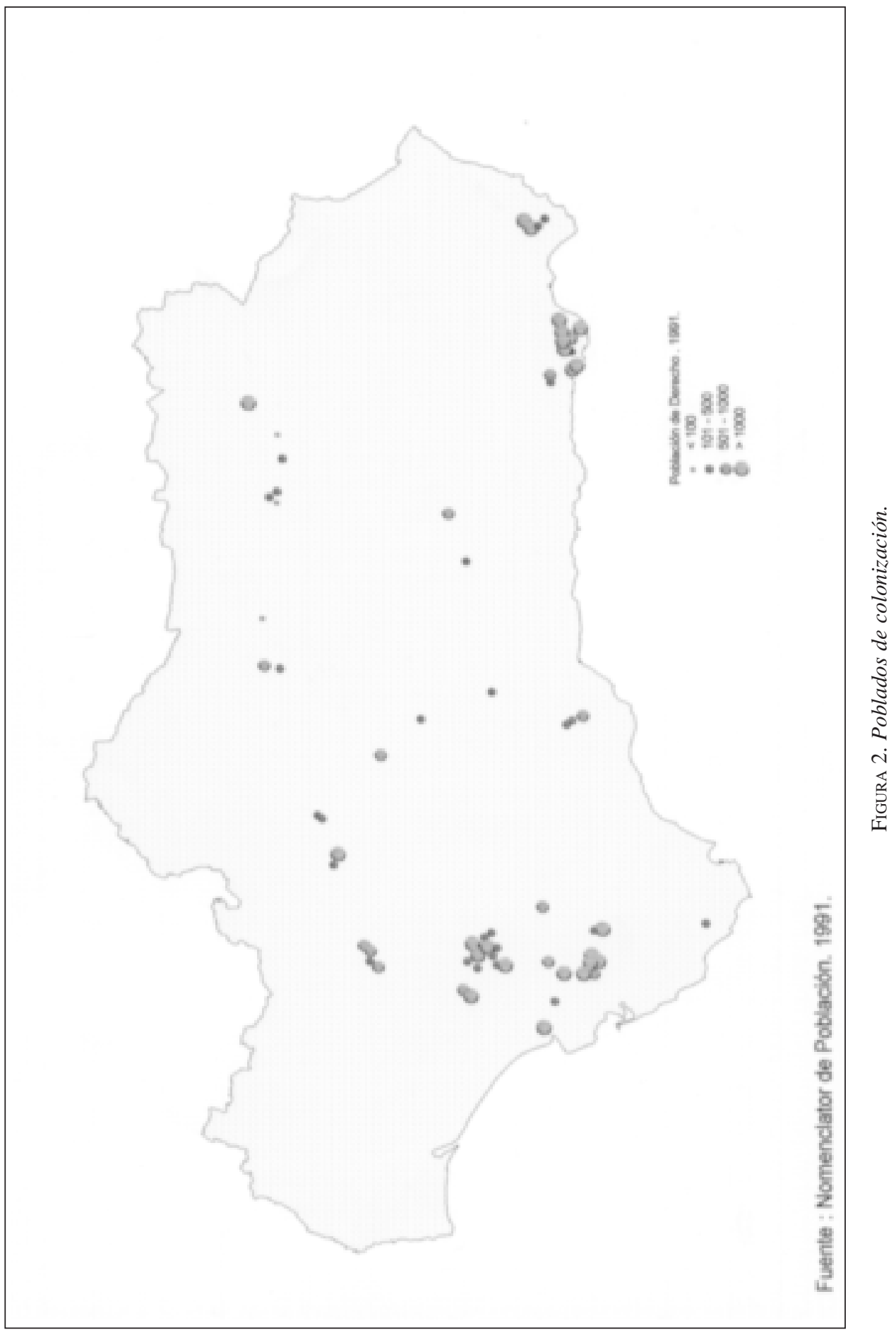


Sin embargo, a partir de los años setenta la transformación en riego y el reparto de parcelas no viene acompañado de la construcción de nuevos poblados. En Andalucía, el caso más claro ha sido el de la Zona Regable del Bajo Guadalquivir, donde en la primera fase se construyeron varios núcleos (Trajano, San Leandro, Marismilla, Vetaherrado, ...), pero en la segunda fase se ha optado por construir nuevas barriadas en algunos de los pueblos de la comarca. De igual modo, ni en el Plan Almonte-Marisma, ni en los nuevos regadíos de El Chanzas, ambos en la provincia de Huelva, el plan de transformación en regadío se ha visto acompañado por la construcción de nuevos poblados.

El elevado coste de la construcción de estos poblados y, sobre todo, la mejora en las comunicaciones y la evolución demográfica de estos asentamientos, que participan plenamente de la tendencia regresiva que afecta en general al mundo rural, llevaron a los planificadores del ahora denominado I.R.Y.D.A. a prescindir de la construcción de nuevos poblados en las zonas regables que se proyectan a partir de entonces.

El mapa con la distribución de los poblados de colonización en Andalucía aparece reflejado en la figura $\mathrm{n}^{\circ} 2$. Como queda dicho, éstos fueron concebidos como núcleos autosuficientes para una población media entre 500 y 1.000 habitantes. En general, han experimentado una tendencia regresiva, y ello teniendo en cuenta que fueron ocupados por población adulta-joven constituida por familias numerosas; pero la falta de identidad de una comunidad incipiente aún, con apenas una o dos decenas de historia propia, y el éxodo rural generalizado en la región se han sumado para provocar su caída demográfica. En general, hoy predominan los núcleos con poblaciones comprendidas entre 250 y 500 habitantes, con tendencia aún regresiva o que han quedado estancados en su crecimiento. Aunque tampoco faltan algunos poblados claramente dinámicos; éstos se localizan preferentemente en la Zona Regable del Guadalcacín, en el término municipal de Jerez de la Frontera (Cádiz); la del Bajo Guadalquivir (sur de la provincia de Sevilla); las del Campo de Dalías y el de Níjar en Almería.

Estos poblados, particularmente los más dinámicos, presentan diversos problemas, en buena medida relacionados con su propia concepción original. Si bien la idea inicial fue que constituyesen núcleos autosuficientes, la propia concepción que se tenía de la autosuficiencia en la época en que estos poblados son planificados y construidos, hace que hoy carezcan de un buen número de servicios e infraestructuras básicos, o que hayan debido ser introducidos con posterioridad, con elevados costes. La falta de viviendas y la dependencia del núcleo principal figuran asimismo entre sus principales problemas; esta misma razón, la dependencia de la cabecera del municipio en donde se ubican, lleva a plantear la segregación municipal, con fuertes tensiones locales.

En cualquier caso, concluido definitivamente el período de construcción de poblados y con una perspectiva de varias decenas de años desde que los primeros colonos se establecieron en algunos de ellos, puede decirse que la políticas de colonización ha dejado sobre el territorio andaluz una herencia de casi 130 nuevos poblados, de los que unos 40 se encuentran plenamente consolidados e integrados en el sistema urbano andaluz.

\section{Valoración económica de las zonas regables de iniciativa pública}

Indiscutiblemente, en relación a los usos agrarios preexistentes en las zonas en las que se ha procedido a su transformación en regadío, el valor de la producción agraria se ha visto considerablemente incrementada: en menor medida en las tierras donde o bien el valor de la producción en secano eran relativamente elevado o las producciones agrarias implantadas en el regadío son de carácter extensivo (buena parte de las vegas y campiñas del Guadalquivir); y en mayor proporción allí donde las tierras permanecían incultas con 
anterioridad a la transformación o sus orientaciones actuales son marcadamente intensivas (Campo de Dalías, por citar el ejemplo más paradigmático). En una aproximación muy global, por tanto, este incremento de la productividad se ha multiplicado por cuatro en las zonas de menor crecimiento y llega a multiplicarse por doce en las que el incremento ha sido mayor.

En relación a las tierras de regadío propiamente dichas, es habitual la valoración, o la crítica, de que las tierras transformadas por iniciativa pública han tendido a orientarse hacia producciones más extensivas; de forma que el «regadío público», se afirma, es menos productivo que el regadío de iniciativa privada. Sin que falten ejemplos que avalen esta afirmación, globalmente consideradas en el conjunto de la región andaluza, la productividad de las Zonas Regables es sensiblemente superior a la media de todos los regadíos andaluces.

Así, la producción media del regadío andaluz se sitúa en torno a las 530.000 pesetas/ hectárea, cifra que se eleva a 650.000 ptas/ha., es decir un 122\% en relación a la media, si se toma en consideración únicamente la producción de las Zonas Regables (Otra valoración distinta, en la que aquí no se entra, es qué diferencia se establece entre la producción y las orientaciones productivas de las tierras de los colonos y de aquellos propietarios que han conservado la propiedad de sus tierras dentro de las Zonas Regables). Y, si se pone en relación a la producción media de los regadíos españoles, la comparación vuelve a ser favorable para los andaluces, ya que la media del todo el regadío español se sitúa en $429.600 \mathrm{ptas} / \mathrm{ha}$.

Ahora bien, a partir de esta primera consideración global, las diferencias son muy acusadas entre unas y otras Zonas Regables, tal como puede apreciarse en la tabla $\mathrm{n}^{\mathbf{0}} 2$. Efectivamente, aquí los extremos se encuentran representados por el Campo de Dalías, en el extremo superior, con una productividad media de 2.417 .000 pesetas/hectárea; y por la Zona Regable de Sierra Boyera, en el norte de la provincia de Córdoba, en el extremo inferior, donde la productividad media se reduce a 216.000 ptas/ha. Pero, si bien este último caso puede considerarse poco representativo, por el reducido tamaño de la zona (1.153 hectáreas) y su ubicación «atípica» en una comarca serrana, no son infrecuentes las Zonas Regables, situadas preferentemente en las campiñas del Guadalquivir, de extensiones considerables y algunas de ellas representantes «ejemplares» de la política de colonización en Andalucía, cuya productividad media desciende por debajo de las 500.000 ptas/ha.

En términos generales, las producciones más extensivas se localizan a lo largo del Valle del Guadalquivir, mientras que las más intensivas se identifican con las tierras de regadío del litoral almeriense, y ahora, de forma creciente y en expansión, con el litoral onubense. Parece claro que su productividad se encuentra directamente relacionada con las orientaciones productivas de estas Zonas Regables: cultivos herbáceos de ciclo anual, como orientación predominante, en el primer caso; y cultivos intensivos de hortalizas y frutales, en el segundo (a riesgo de caer en una excesiva generalización con esta afirmación). Profundizar en las razones de esta especialización productiva comarcal dentro de los regadíos andaluces, y ponerlo en relación con hábitos o prácticas culturales tradicionales, con la estructura de la propiedad dominante, con la implantación de canales de comercialización, u otros argumentos, exigiría de un desarrollo, que difícilmente tendría cabida en esta comunicación.

La eficacia del regadío puede asimismo ser valorada a partir de otros parámetros, como los de empleo y consumo de agua, que aparecen asimismo recogidos en la tabla 2.

La relación entre producción y empleo (ver figura 3) resulta ser una relación prácticamente directa, por lo que apenas entraremos en su comentario: las Zonas Regables en las que se obtiene una productividad media más alta por hectárea son también las que generan mayor número de jornales por unidad de superficie; y también a la inversa. Si algún dato debe ser destacado del gráfico es la concentración de Zonas Regables en los cuadrantes 
Tabla 2

BALANCE SOCIOECONÓMICO DE LAS ZONAS REGABLES

DE INICIATIVA PÚBLICA EN ANDALUCÍA

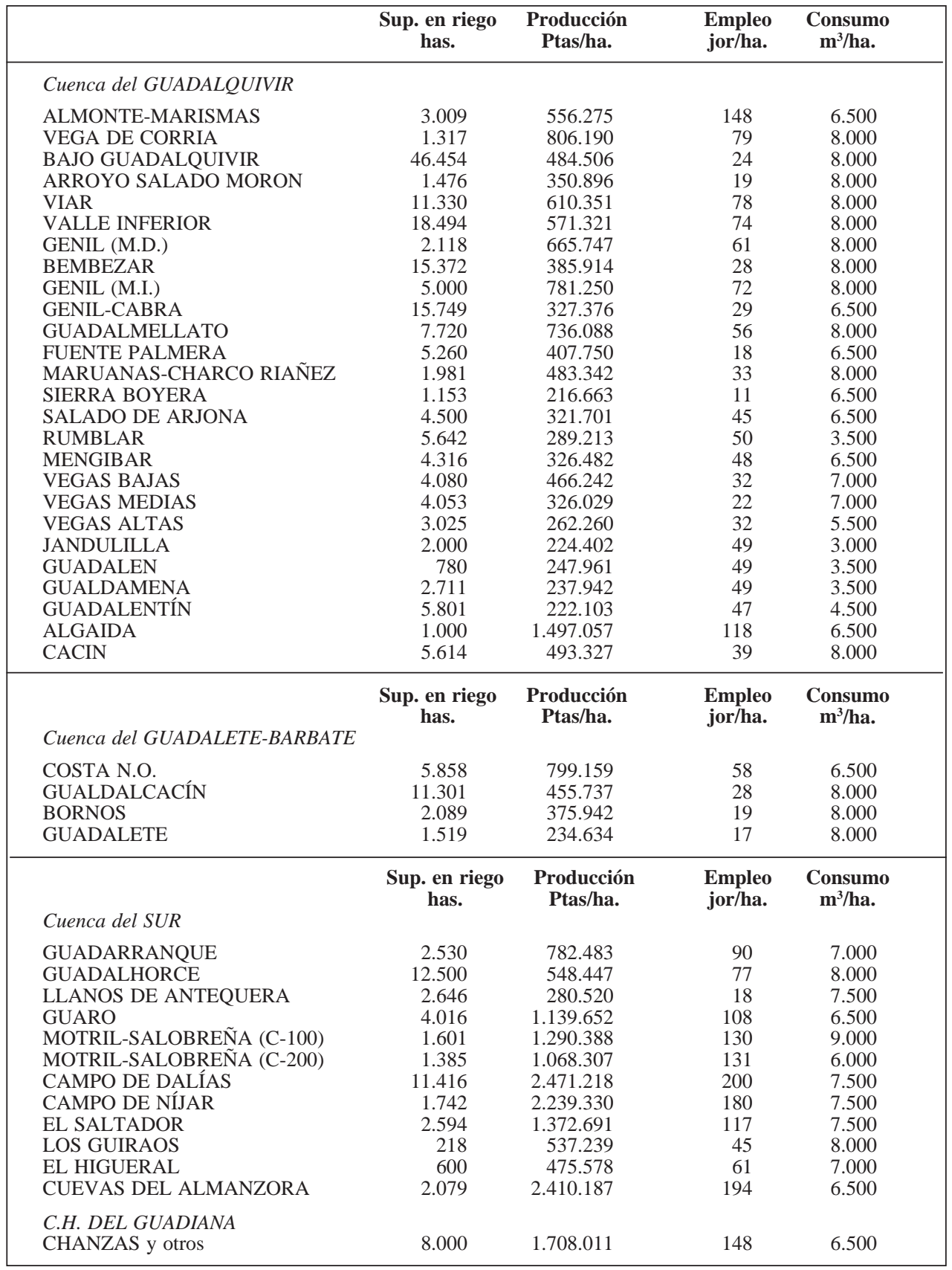

Fuente: I.A.R.A., 1994. 


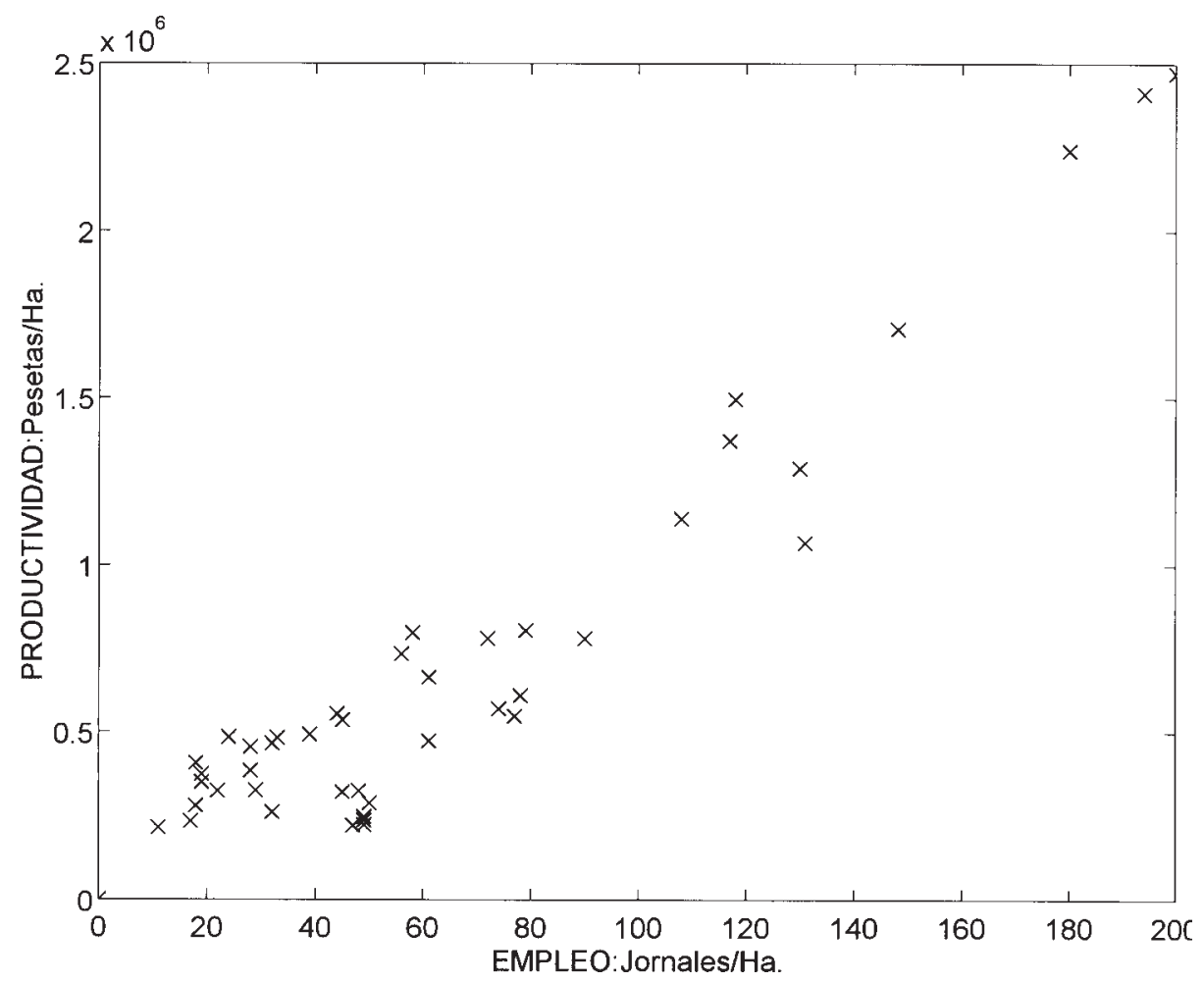

Figura 3. Regadío público en Andalucía. Relación entre productividad y empleo.

inferiores: por debajo del millón de pesetas por hectárea y de los ochenta jornales/ha. se sitúan más del 75\% de las Zonas Regables.

En cambio, no es ni mucho menos tan directa la relación que se establece entre productividad y empleo, por una parte, y consumo de agua por otro. Hay un grupo importante de Zonas Regables con bajo consumo de agua y baja producción, tales como Jandulilla, Guadalén, Guadelentín, Rumblar o Vegas Altas, entre otras. Pero en mayor medida que éstas, como escasamente eficaces han de ser consideradas aquellas zonas en las que el consumo de agua es elevado ( $8.000 \mathrm{~m}^{3} / \mathrm{Ha}$.), mientras que su producción es baja. En esta situación se encuentran las Zonas Regables del Guadalete, Arroyo Salado de Morón, Bornos, Bembézar, Guadalcacín, Maruanas, Bajo Guadalquivir o Zona Regable del Cacín; algunas de las cuales, como ya se advertía anteriormente, se identifican con los casos más «ejemplares» de la política de colonización en la región. Y a tenor de este criterio, destacan algunas Zonas Regables de mayor eficacia: la productividad y el empleo generado es elevado, pero es relativamente bajo el consumo de agua (en torno a $6.500 \mathrm{~m}^{3} / \mathrm{Ha}$.); en esta situación se encuentran las Zonas Regables de las Cuevas de Almanzora, Motril-Salobreña C-200, Guaro, Algaida y Chanzas.

Dentro de la reserva con la habitualmente que deben ser tomados los datos disponibles sobre estos parámetros de producción, trabajo y consumo de agua en el regadío, es evidente que existen notables diferencias entre unas y otras Zonas Regables, y que ello debe constituir elementos de valoración en futuras decisiones sobre política de regadío. 


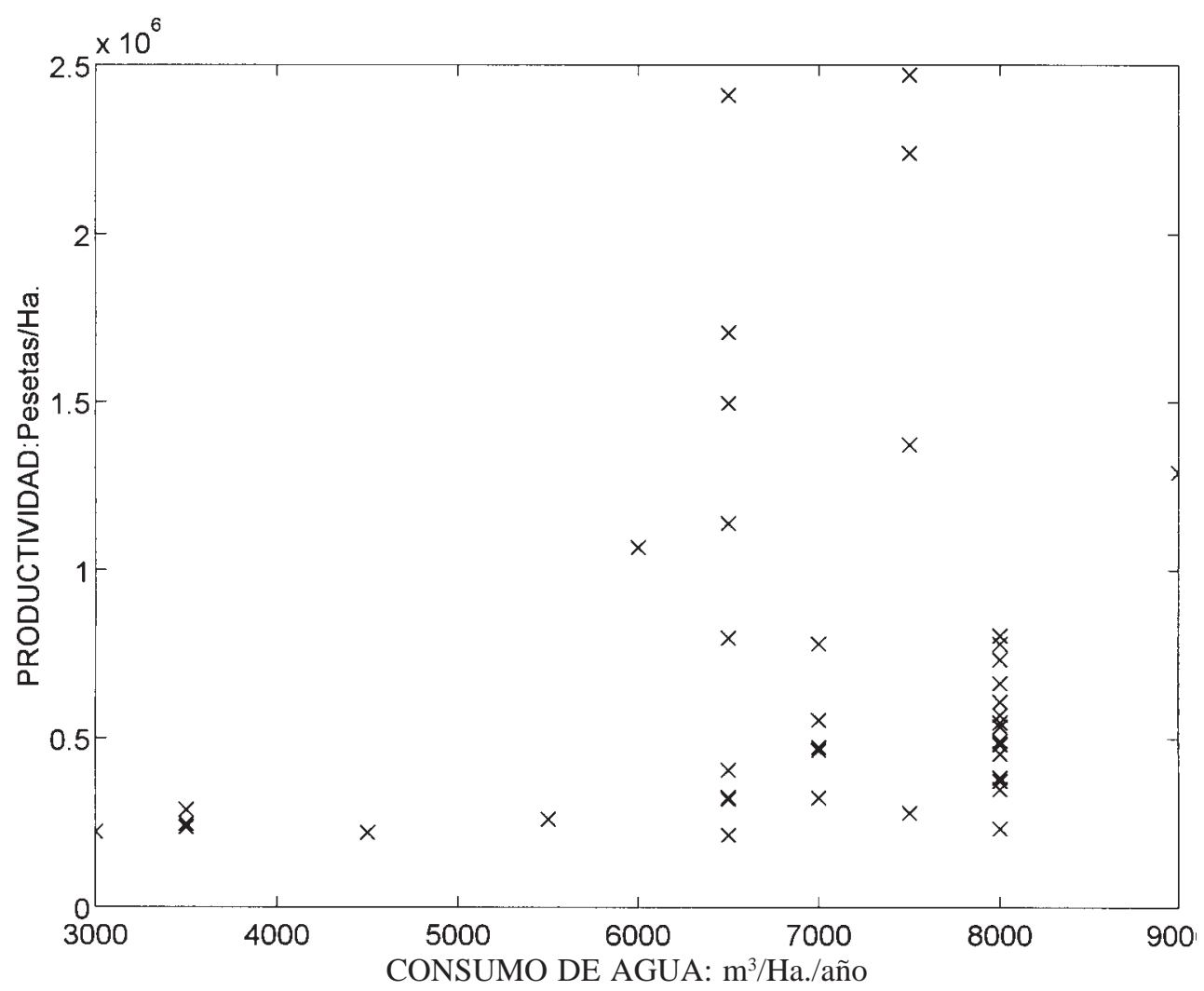

FIgURa 4. Regadío público en Andalucía. Relación entre productividad y consumo de agua.

\section{Valoración final}

En suma, pues, Andalucía se ha beneficiado a lo largo de toda la presente centuria de una política de colonización con resultados diversos. Si bien desde los primeros decenios se registran distintas operaciones de asentamiento de colonos y transformación productiva de las tierras colonizadas, esta política concentra en el tercer cuarto del siglo el mayor volumen de sus intervenciones, vinculadas a la política de Grandes Zonas Regables desarrollada por el Instituto Nacional de Colonización. Sin embargo, el hecho de que no se trate de una política concebida a mitad de siglo, sino que tenga sus antecedentes y primeras intervenciones en los decenios anteriores no es, en absoluto, una cuestión intrascendente, ya que la política concebida en la década de los cuarenta, y ejecutada en los cincuenta, sesenta y hasta los setenta, se inspira en los principios y en las condiciones socioeconómicas y territoriales de la España de las décadas precedentes, en algunos casos quizás por pura inercia o por la lentitud de las operaciones que se desarrollaban.

Así, la decisión de asentar a los colonos en poblados autosuficientes, levantados de nueva planta, podría haberse realizado con otros criterios si hubiese sido una política pensada ex-novo a partir de la realidad social y económica de la época en la que se ejecutan. En cualquier caso, no deja de ser una realidad la aportación de la política de colonización al mapa del poblamiento en Andalucía: han sido construido unos 130 nuevos 


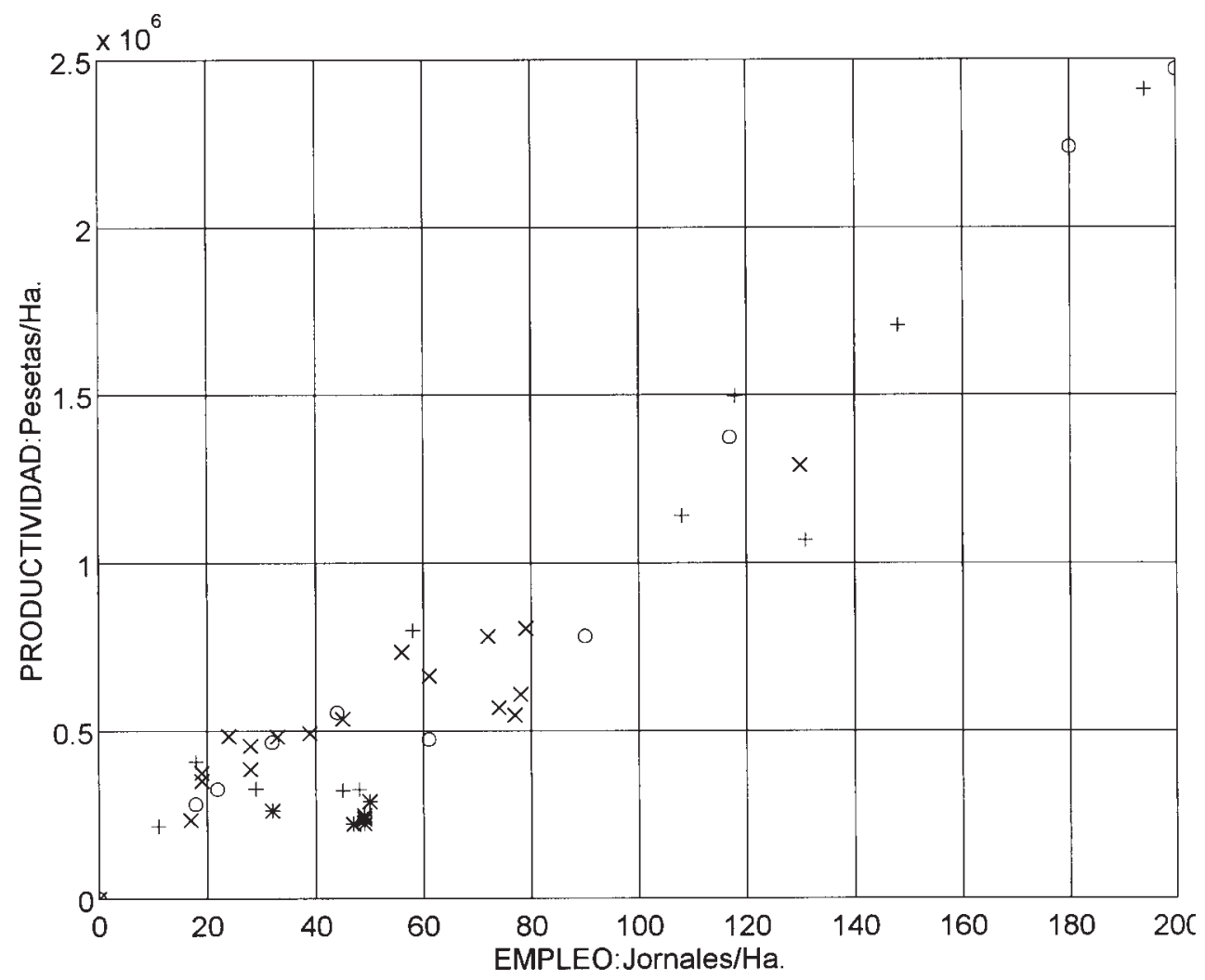

FIgURA 5. Regadío público en Andalucía. Relación entre productividad y empleo y consumo de agua.

poblados, de los cuáles, aproximadamente la tercera parte se han consolidado como núcleos de población de cierta entidad, se han integrado en el sistema urbano regional y, en algunos casos, han pasado a constituirse en municipios independientes, superando en su dinámica demográfica y económica a las cabeceras de municipio de las que inicialmente dependían.

La política de colonización ha sido, también, la responsable directa de la transformación en regadío de más de 250.000 hectáreas, que suponen el $40 \%$ de la superficie regada de la región. Y además se encuentra actualmente en transformación, por iniciativa pública, otras 80.000 hectáreas. Siempre podría discutirse si la intervención pública ha suplido una intervención que en cualquier caso se hubiera producido por iniciativa privada, o si ha sido impulsora de esta última: pueden citarse ejemplos en ambos sentidos. Pero, en algún caso que hemos estudiado con más detenimiento (Plan Almonte-Marismas), concluíamos que la intervención pública había sido motor del desarrollo del regadío privado y cuando, por razones de compatibilidad medioambiental, la transformación pública se frena, el riego privado ha continuado creciendo.

Hoy se discute si el regadío andaluz ha llegado a su «techo», tanto por la superficie ya en riego, como por la disponibilidad de recursos hídricos o por el freno que aparentemente supone la orientación más extensiva de la política agraria comunitaria, bien por razones de superproducción, bien por razones de conservación medioambiental. Discusión en la que, 
como uno de sus principales argumentos, se hace intervenir la eficacia del regadío en términos económicos, sociales o de consumo de agua, como se ha pretendido hacer en esta comunicación. Con ser importante el argumento de la eficacia, expresado en unos u otros términos, o la nueva orientación de la política agraria de la Unión Europea, no deben ser los únicos factores ni los principales a tomar en consideración. El valor estratégico de la producción de alimentos; el carácter de factor de producción que tiene el agua en una agricultura como la nuestra, donde las temperaturas apenas imponen límite a la producción, pero sí la escasez de agua; o la importancia que una agricultura rentable (aunque sea en los términos de rentabilidad que tiene en el caso ya comentado de Sierra Boyera en Córdoba) puede tener en el equilibrio territorial; son razones que también deben ser sopesadas a la hora de orientar la política de regadío hoy en Andalucía.

\section{Bibliografía}

ACTUACIONES llevadas a cabo en materia de reforma agraria por los organismos antecesores al IARA dentro de la Comunidad Autónoma Andaluza (1988): Sevilla, Instituto Andaluz de Reforma Agraria, ejemplar mimeo.

COMISION INTERNACIONAL DE EXPERTOS SOBRE EL DESARROLLO DEL ENTORNO DE DOÑANA (1992): Dictamen sobre estrategias para el desarrollo socioeconómico sostenible del Entorno de Doñana. Sevilla, Consejería de Obras Públicas y Transportes.

COROMINAS MASIP, J. (1992): El regadío, ¿una opción de desarrollo local? Ejemplar mimeo.

CRUZ VILLALÓN, J. (1993): «Del Instituto Nacional de Colonización (1939) al Plan Forestal Andaluz (1989), en GIL OLCINA, A. y MORALES GIL, A.: Medio Siglo de Cambios Agrarios en España. Alicante, Instituto de Cultura Juan Gil Albert, pp. 677-697.

CRUZ VILLALÓN, J. (1994): «La influencia del regadío en el equilibrio territorial», en Symposium Nacional Presente y Futuro de los regadíos españoles. Madrid, Colegio Oficial de Ingenieros Agrónomos.

ENTIDADES Menores de Población de Andalucía (1991): Sevilla, Consejería de Obras Públicas y Transportes/Dirección General de Urbanismo.

MOCLUS, F.J. y OYÓN, J.L. (1988): Políticas y técnicas en la ordenación del espacio rural. Madrid, Ministerio de Agricultura, Pesca y Alimentación/Ministerio para las Administraciones Públicas/ Ministerio de Obras Públicas y Urbanismo.

MORAL ITUARTE, L. del (1994): «Política de regadío y planificación territorial: planteamiento del problema», en Symposium Nacional Presente y Futuro de los regadíos españoles. Madrid, Colegio Oficial de Ingenieros Agrónomos.

NAREDO PÉREZ, J.M.; LÓPEZ GÁLVEZ, J. y MOLINA HERRERA, J. (1993): «La gestión del agua para el regadío. El caso de Almería», en El Boletín, no 9, pp. 15-22.

PRADOS VELASCO, M.J. (1995): «Las agriculturas productivas. Una visión crítica del regadío andaluz», en RAMOS LEAL, E. y CRUZ VILLALÓN, J. (Coords.): Hacia un nuevo sistema rural. Madrid, Ministerio de Agricultura, Pesca y Alimentación, pp. 661-687.

PROBLEMÁTICA territorial de las entidades menores de población. Formulación de criterios para la modificación de términos municipales (1991): Sevilla. Consejería de Obras Públicas y Transportes, Dirección General de Ordenación del Territorio.

VERDE CASANOVA, J.E. (1994): «Estimación de la producción total agrícola en los regadíos españoles y su distribución por cuencas hidrográficas; ptas $/ \mathrm{m}^{3}$ agua aplicada», en Symposium Nacional Presente y Futuro de los regadíos españoles. Madrid, Colegio Oficial de Ingenieros Agrónomos.

VILLANUEVA PAREDES, A. y LEAL MALDONADO, J. (1990): La planificación del regadío y los pueblos de colonización. Madrid, Ministerio de Agricultura, Pesca y Alimentación/Ministerio para las Administraciones Públicas/ Ministerio de Obras Públicas y Urbanismo.

ZONAS Regables de iniciativa pública en Andalucía (1994): Sevilla, Instituto Andaluz de Reforma Agraria, ejemplar mimeo. 